Pacific Northwest

National Laboratory

Operated by Battelle for the

U.S. Department of Energy

\title{
Ultrasonic Examination of Double-Shell Tank 241-AW-103 Examination Completed September 2006
}

\author{
AF Pardini \\ DR Weier \\ GJ Posakony
}

April 2007

Prepared for the U.S. Department of Energy under Contract DE-AC05-76RL01830 


\section{DISCLAIMER}

This report was prepared as an account of work sponsored by an agency of the United States Government. Neither the United States Government nor any agency thereof, nor Battelle Memorial Institute, nor any of their employees, makes any warranty, express or implied, or assumes any legal liability or responsibility for the accuracy, completeness, or usefulness of any information, apparatus, product, or process disclosed, or represents that its use would not infringe privately owned rights. Reference herein to any specific commercial product, process, or service by trade name, trademark, manufacturer, or otherwise does not necessarily constitute or imply its endorsement, recommendation, or favoring by

the United States Government or any agency thereof, or Battelle Memorial Institute. The views and opinions of authors expressed herein do not necessarily state or reflect those of the United States Government or any agency thereof.

PACIFIC NORTHWEST NATIONAL LABORATORY

$$
\begin{gathered}
\text { operated by } \\
\text { BATTELLE } \\
\text { for the }
\end{gathered}
$$

UNITED STATES DEPARTMENT OF ENERGY under Contract DE-AC05-76RL01830

Printed in the United States of America Available to DOE and DOE contractors from the

Office of Scientific and Technical Information, P.O. Box 62, Oak Ridge, TN 37831-0062; ph: (865) 576-8401 fax: (865) 576-5728

email: reports@adonis.osti.gov

Available to the public from the National Technical Information Service,

U.S. Department of Commerce, 5285 Port Royal Rd., Springfield, VA 22161 ph: (800) 553-6847 fax: (703) 605-6900

email: orders@ntis.fedworld.gov online ordering: http://www.ntis.gov/ordering.htm This document was printed on recycled paper. 


\title{
Ultrasonic Examination of Double-Shell Tank 241-AW-103 Examination Completed September 2006
}

\author{
AF Pardini \\ GJ Posakony \\ DR Weier
}

April 2007

Prepared for

the U.S. Department of Energy

under Contract DE-AC05-76RL01830

Pacific Northwest National Laboratory

Richland, Washington 99352 


\section{Summary}

AREVA NC Inc. (AREVA), under a contract from CH2M Hill Hanford Group (CH2M Hill), has performed an ultrasonic examination of selected portions of Double-Shell Tank 241-AW-103. The purpose of this examination was to provide information that could be used to evaluate the integrity of the wall of the primary and secondary tank. The requirements for the ultrasonic examination of Tank 241AW-103 were to detect, characterize (identify, size, and locate), and record measurements made of any wall thinning, pitting, or cracks that might be present in the wall of the primary tank and the wall of the secondary tank. Any measurements that exceed the requirements set forth in the Engineering Task Plan (ETP), RPP-Plan-27202 (Jensen 2005) and summarized on page 1 of this document, are to be reported to CH2M Hill and the Pacific Northwest National Laboratory (PNNL) for further evaluation. Under the contract with CH2M Hill, all data is to be recorded on electronic media and paper copies of all measurements are provided to PNNL for third-party evaluation. PNNL is responsible for preparing a report(s) that describes the results of the AREVA ultrasonic examinations.

\section{Examination Results}

The results of the examination of Tank 241-AW-103 have been evaluated by PNNL personnel. The primary tank ultrasonic examination consisted of two vertical 15-in.-wide scan paths over the entire height of the tank, the heat-affected zone (HAZ) of four vertical welds and one horizontal weld from Riser 29 and two vertical 15-in.-wide scan paths over the entire height of the tank from Riser 28. Additionally, two vertical 15-in.-wide scan paths over the entire height of the secondary tank from Riser 28 were performed. The examinations were performed to detect any wall thinning, pitting, or cracking in the primary tank wall.

\section{Primary Tank Wall Vertical Scan Paths}

Two 15-in.-wide vertical scan paths were performed on Plates \#1, \#2, \#3, \#4, and \#5 from Riser 28. The plates were examined for wall thinning, pitting, and cracks oriented vertically on the primary tank wall. There were no areas of wall thinning that exceeded the reportable level of $10 \%$ of the nominal thickness. No pitting or vertical crack-like indications were detected in Plates \#1, \#2, \#3, \#4, or \#5.

Two 15-in.-wide vertical scan paths were performed on Plates \#1, \#2, \#3, \#4, and \#5 from Riser 29. The plates were examined for wall thinning, pitting, and cracks oriented vertically on the primary tank wall. There were no areas of wall thinning that exceeded the reportable level of $10 \%$ of the nominal thickness. No pitting or vertical crack-like indications were detected in Plates \#1, \#2, \#3, \#4, or \#5.

\section{Primary Tank Wall Weld Scan Paths}

The HAZ of vertical welds in Plates \#2, \#3, \#4, and \#5 from Riser 29 were examined for wall thinning, pitting, and cracks oriented either perpendicular or parallel to the weld. There were no areas of 
wall thinning that exceeded the reportable level of $10 \%$ of the nominal thickness. No pitting or cracklike indications were detected in the weld HAZ areas in Plates \#2, \#3, \#4, and \#5.

The HAZ of the horizontal weld between Plate \#5 and the tank knuckle from Riser 29 was examined for wall thinning, pitting and cracks oriented either perpendicular or parallel to the weld. There were no areas of wall thinning that exceeded the reportable level of $10 \%$ of the nominal thickness. No pitting or crack-like indications were detected in the weld HAZ areas on Plate \#5 side or on the knuckle side of the horizontal weld.

\section{Secondary Tank Wall Scan Paths}

Two 15-in.-wide vertical scan paths were performed on the secondary tank wall on Plates \#1, \#2, \#3, \#4, and \#5 from Riser 28. The plates were examined for wall thinning, pitting, and cracks oriented vertically on the secondary tank wall. There were no areas of wall thinning that exceeded the reportable level of $10 \%$ of the nominal thickness. No pitting or vertical crack-like indications were detected in Plates \#1, \#2, \#3, \#4, or \#5.

\section{Extreme Value Analysis}

Extreme value measured wall thickness losses were estimated. Since current remaining wall thickness typically still exceeds drawing nominal, thereby generating negative losses, UT image maximum values were instead used to determine estimated nominal wall thickness per plate/riser combination. These thicknesses tended to run about 0.030 to 0.050 -in. greater than drawing nominal. They in turn were used with each UT image minimum value to determine estimated wall thickness losses which were then combined for a plate course over the two risers, two UT measurement paths per riser.

Three parameter Weibull distributions were fit to plate course measurements as well as to the measurements combined over all plates. The latter case leads to a proposed worst case measured wall thickness loss of 0.080 -in. that might be expected if the entire surface area of the tank wall were UT inspected. A 95\% confidence bound is computed based on the uncertainty in the Weibull parameters caused by the relatively minimal amounts of data for distribution fitting and the quality of the Weibull fit; this $95 \%$ bound on measured wall thickness loss is 0.086 -in. Note that such losses should be considered relative to the larger "estimated" nominal wall thicknesses and not the drawing nominal.

Three rather large outlying losses for Plate \#1 bring into some question the suitability of combining this plate with the others to obtain these combined extreme value estimates. However, when Plate \#1 is treated alone, a large number of quite small losses, combined with three large outlying values, results in a poor distributional fit and quite large extreme values for the plate by itself. Insufficient data are available to identify the preferred approach between combining plate measurements or isolating those from Plate $\# 1$. 


\section{Contents}

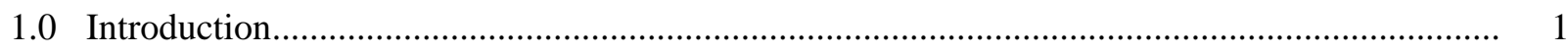

2.0 Qualified Personnel, Procedures, and Equipment........................................................... 2

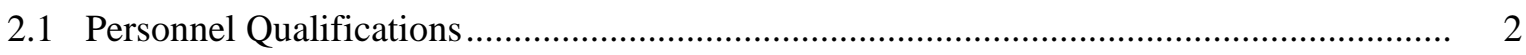

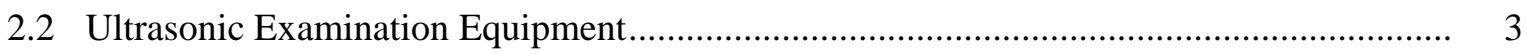

2.3 Ultrasonic Examination Procedure _................................................................................ 3

3.0 Ultrasonic Examination Configuration ...................................................................... 4

3.1 Primary Tank Wall Transducer Configuration ............................................................. 4

3.2 Weld Zone Transducer Configuration .............................................................................. 5

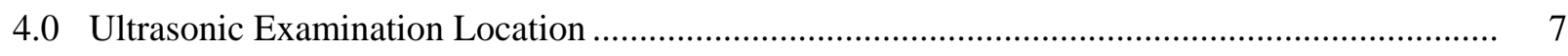

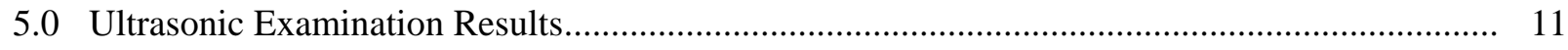

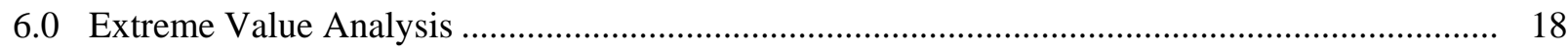

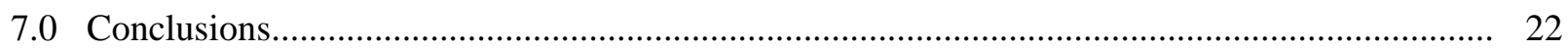

7.1 Primary Tank Wall Vertical Scan Paths .................................................................... 22

7.2 Primary Tank Wall Weld Scan Paths ........................................................................ 22

7.3 Secondary Tank Wall Vertical Scan Paths ................................................................... 23

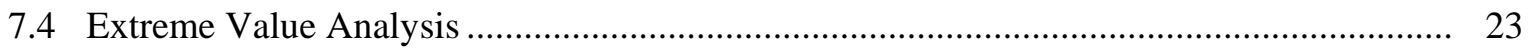

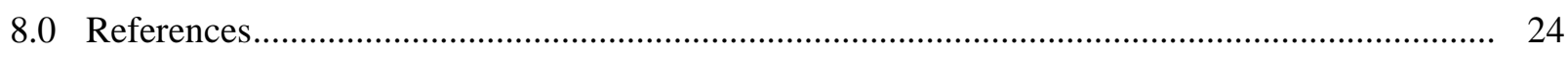




\section{Figures}

3.1 Transducer Configuration for Examining the Primary and Secondary Tank Walls

3.2 Transducer Configurations for Examination of Weld Zone in the Primary Tank Wall........... 5

3.3 Views of the Weld Zone to be Ultrasonically Examined in the Primary Tank Wall .............. 6

4.1 UT of Tank 241-AW-103 Riser 28 and Riser 29 .......................................................... 7

4.2 Sketch of Scan Paths on Tank 241-AW-103 Primary Tank from Riser 28........................... 8

4.3 Sketch of Scan Paths on Tank 241-AW-103 Primary Tank from Riser 29........................... 9

4.4 Sketch of Scan Paths on Tank 241-AW-103 Secondary Tank from Riser 28....................... 10

5.1 UT Data from Tank 241-AW-103 Primary Tank Riser 28 .............................................. 12

5.2 UT Data from Tank 241-AW-103 Primary Tank Riser 28 cont. ......................................... 13

5.3 UT Data from Tank 241-AW-103 Primary Tank Riser 29 ................................................ 14

5.4 UT Data from Tank 241-AW-103 Primary Tank Riser 29 cont. ........................................... 15

5.5 UT Data from Tank 241-AW-103 Secondary Tank Riser 28 .......................................... 16

5.6 UT Data from Tank 241-AW-103 Secondary Tank Riser 28 cont. ....................................... 17

6.1 Table of Estimated Nominal Thickness from UT Maxima .................................................. 18

6.2 Weibull Distribution Fits to UT Maximum Wall Thickness Loss by Plate Course ................ 19

6.3 Table of Tank 241-AW-103 Wall Thickness Extreme Value Loss Estimates and Bounds..... 20

6.4 Weibull Distribution Fit to Maximum Wall Thickness Loss Combined over Plate Courses... 21 


\subsection{Introduction}

AREVA NC Inc. (AREVA), under a contract from CH2M Hill Hanford Group (CH2M Hill), has performed an ultrasonic examination (UT) of selected portions of Double-Shell Tank (DST) 241-AW103. The purpose of this examination was to provide information that could be used to evaluate the integrity of the DST. The requirements for the UT of Tank 241-AW-103 were to detect, characterize (identify, size, and locate), and record measurements made of any wall thinning, pitting, or cracks that might be present in the wall of the primary tank and the wall of the secondary tank. Any measurements that exceed the requirements set forth in the Engineering Task Plan (ETP), RPP-Plan-27202 (Jensen 2005), are to be reported to CH2M Hill and the Pacific Northwest National Laboratory (PNNL) for further evaluation. Specific measurements that are reported include the following:

- Wall thinning that exceeds $10 \%$ of the nominal thickness of the plate.

- Pits with depths that exceed $25 \%$ of the nominal plate thickness.

- Stress-corrosion cracks that exceed 0.10 in. (through-wall) and are detected in the inner wall of the tank, HAZ of welds, or in the tank knuckle.

The accuracy requirements for ultrasonic measurements for the different types of defects are as follows:

- Wall thinning - measure thickness within \pm 0.020 in.

- Pits - size depths within \pm 0.050 in.

- Cracks - size the depth of cracks on the inner wall surfaces within $\pm 0.1 \mathrm{in}$.

- Location - locate all reportable indications within \pm 1.0 in.

Under the contract with CH2M Hill, all data is to be recorded on electronic media and paper copies of all measurements are provided to PNNL for third-party evaluation. PNNL is responsible for preparing a report(s) that describes the results of the AREVA UT. 


\subsection{Qualified Personnel, Procedures, and Equipment}

Under contract from CH2M Hill, qualification of personnel participating in the DST inspection program, the UT equipment (instrument and mechanical scanning fixture), and the UT procedure that will be used in the examination of the current DST is required. Personnel participating in the examinations are to be certified in accordance with American Society for Nondestructive Testing (ASNT) Recommended Practice SNT-TC-1A, 1992 Edition, and associated documentation is to be provided. The capability of the UT system is to be validated through a performance demonstration test (PDT) on a mock-up simulating the actual DST. The current procedure for the UT is to be based on requirements listed in the American Society for Mechanical Engineers (ASME), Boiler and Pressure Vessel Code Section V, Article 4, Ultrasonic Examination Methods for Inservice Inspection.

\subsection{Personnel Qualifications}

The following individuals were qualified and certified to perform UT of the Hanford DST 241-AW103:

- Mr. Wesley Nelson, ASNT Level III (\#LM-1874) in UT, has been identified as AREVA's UT Level III authority for this project. Mr. Nelson has been certified by AREVA as a UT Level III in accordance with AREVA procedure COGEMA-SVCP-PRC-014, latest revision which conforms to the requirements of ASNT SNT-TC-1A, 1992. Further documentation has been provided to establish his qualifications (Pardini 2000).

- Mr. James B. Elder, ASNT Level III (\#JM-1891) in UT, has been contracted by AREVA to provide peer review of all DST UT data. Mr. Elder has been certified by JBNDT as a UT Level III in accordance with JBNDT written practice JBNDT-WP-1, latest revision. Further documentation has been provided to establish his qualifications (Posakony and Pardini 1998).

- Mr. William D. Purdy, AREVA UT Level II limited (for P-Scan data acquisition only). Mr. Purdy has been certified in accordance with AREVA procedure COGEMA-SVCP-PRC-014, latest revision. Further documentation has been provided to establish his qualifications (Posakony 2001).

The following individuals participated in this examination and are trainees and are not qualified or certified to perform independent UT of the Hanford DST 241-AW-103:

- Mr. Jeffery S. Pintler, AREVA UT trainee in accordance with AREVA procedure COGEMASVCP-PRC-014, latest revision.

- Ms. Laura A. Sepich, AREVA UT trainee in accordance with AREVA procedure COGEMA-SVCPPRC-014, latest revision. 


\subsection{Ultrasonic Examination Equipment}

CH2M Hill has provided the UT equipment for the examination of Tank 241-AW-103. This equipment consists of a Force Institute P-Scan ultrasonic test instrument and Force Institute AWS-5D remote-controlled, magnetic-wheel crawler for examining the primary and secondary tank walls. Ultrasonic transducers used for the examinations are commercially available. The P-Scan ultrasonic system has been qualified through a PDT administered by PNNL. (Posakony and Pardini 1998)

\subsection{Ultrasonic Examination Procedure}

AREVA has provided the UT procedure for the examination of Tank 241-AW-103. This procedure, COGEMA-SVUT-INS-007.3, Revision 3, outlines the type of UT and mechanical equipment that are to be used as well as the types of transducers. Both straight-beam and angle-beam transducers are used for the examination of the primary and secondary tank walls. The examination procedures include full documentation on methods for calibration, examination, and reporting. Hard copies of the T-Scan (thickness) and P-Scan (projection or angle beam) views of all areas scanned are made available for analysis. The UT procedure requires the use of specific UT transducers for the different examinations. A calibration performed before and after the examinations identifies the specific transducers used and the sensitivity adjustments needed to perform the inspection. The AREVA UT procedure has been qualified through a PDT (Posakony and Pardini 1998). 


\subsection{Ultrasonic Examination Configuration}

AREVA is required to inspect selected portions of the DSTs which may include the primary and secondary tank walls, the HAZ of the primary tank vertical and horizontal welds, and the tank knuckle and bottoms. The P-Scan system has been configured to perform these examinations and has been performance tested. The examination of Tank 241-AW-103 included UT of the primary and secondary tank walls and the HAZ of selected welds in the primary tank wall.

\subsection{Primary and Secondary Tank Wall Transducer Configuration}

Figure 3.1 provides an example of the scanning configuration generally used during an examination of the primary and secondary tank walls. However, other configurations can be used at the discretion of the AREVA UT Level III (i.e., 45-degree transducers can be removed for simple wall thickness measurements). The functional diagram in Figure 3.1 shows one straight-beam and two angle-beam transducers ganged together for examining the primary tank wall. The straight beam is designed to detect and record wall thinning and pits, and the angle beams are designed to detect and record any cracking that may be present. These transducers are attached to the scanning bridge and they all move together. Information is captured every 0.035-in. (or as set by the UT inspector) as the assembly is scanned across a line. At the end of each scan line the fixture is indexed 0.035-in. (or as set by the UT inspector) and the scan is repeated. The mechanical scanning fixture is designed to scan a maximum of approximately 15in. and then index for the next scan. The hard copy provides a permanent record that is used for the subsequent analysis.

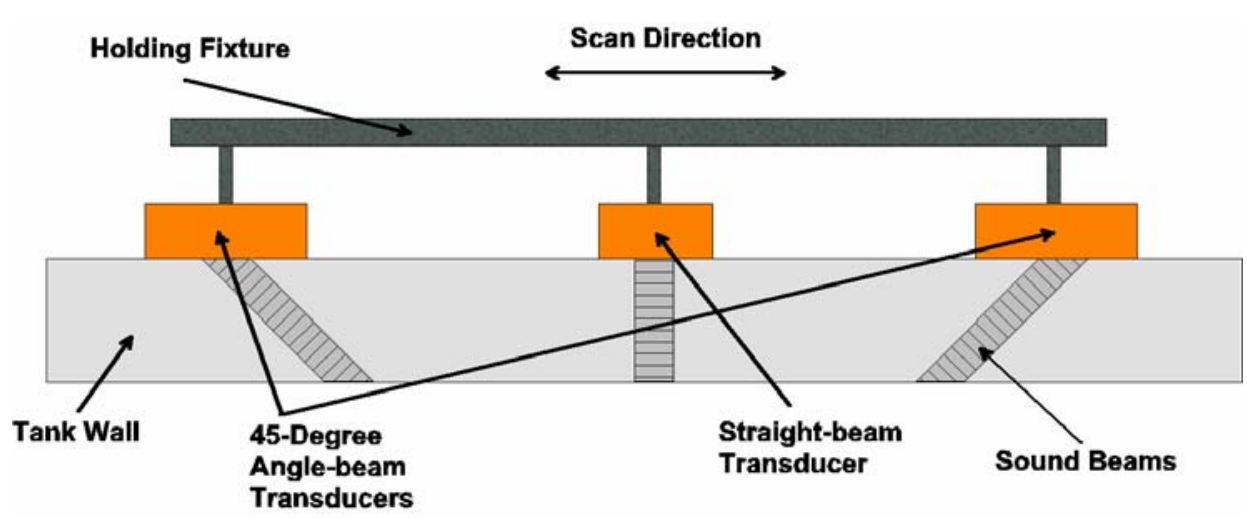

Figure 3.1. Transducer Configuration for Examining the Primary and Secondary Tank Walls

\section{Transducer Specifications:}

Angle-Beam

Type: MWB-45 04E

Frequency: $4 \mathrm{MHz}$

Size: 8 X $9 \mathrm{~mm}$

Manufacturer: Krautkramer

Straight-Beam

Type: MSEB 5B

Frequency: $5 \mathrm{MHz}$

Size: Dual - 9 X 2 mm

Manufacturer: Krautkramer 


\subsection{Weld Zone Transducer Configuration}

Figure 3.2 is a functional sketch that shows the configurations for examination of the weld zone. The area of interest (HAZ of the weld) is shown as lying adjacent to the weld. Both cracks and pitting may occur in this region. The "A" portion of this sketch shows the 60-degree angle-beam transducers used for detecting cracks parallel to the weld. The straight-beam transducers in this sketch are used for detecting and recording any pitting or wall thinning that may be present. All transducers are ganged together. The scanning distance traveled is limited to a total of approximately 5.0-in. The sketch titled "B" shows the arrangement for detecting cracks that may lie perpendicular to the weld. Four 45-degree, angle-beam transducers are used for this inspection. Again the transducers are ganged together but the scan is limited to a total of approximately 4.0-in. The weld zone requirements are shown in Figure 3.3. The scan protocol, data capture, and index parameters are the same for examining other weld areas in the tank.

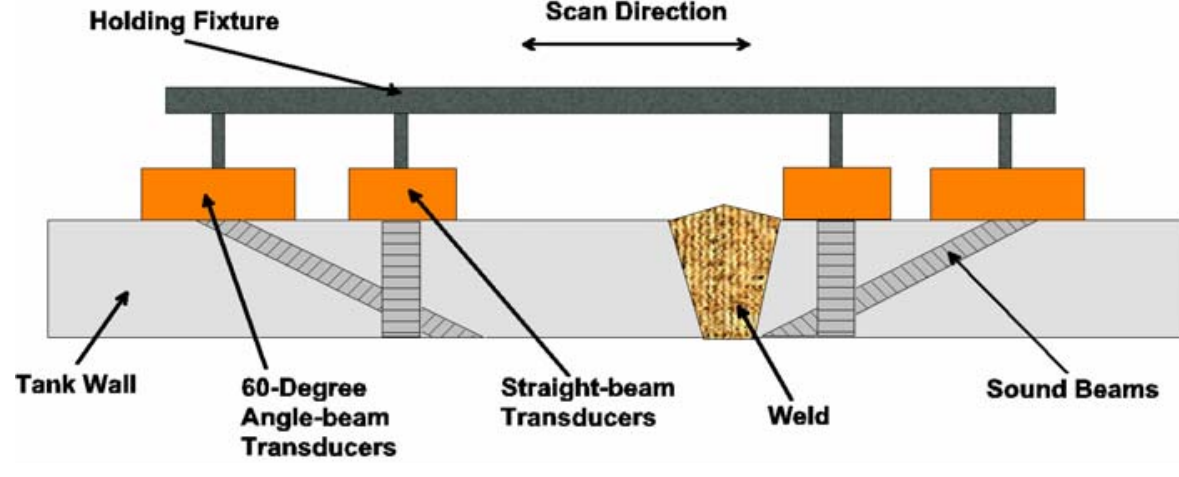

A. Configuration for pitting and cracks parallel to weld

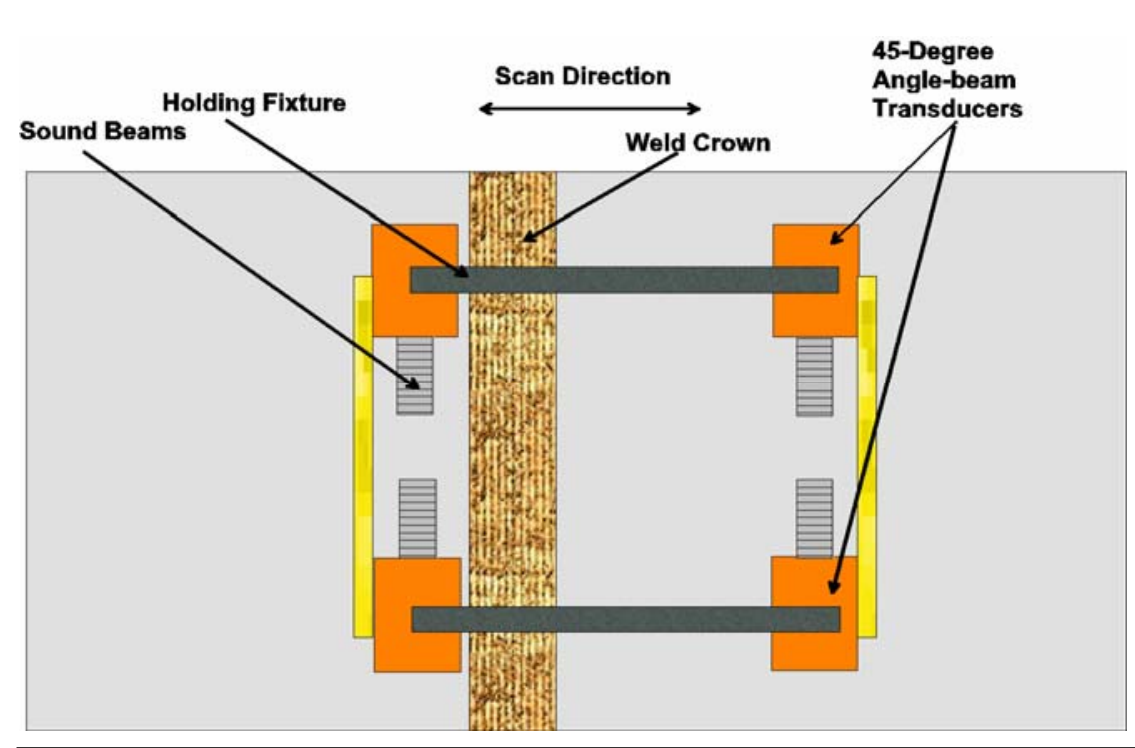

B. Configuration for cracks perpendicular to weld

\section{Transducer Specifications:}

Angle-Beam

Type: MWB-60 04E

Frequency: $4 \mathrm{MHz}$

Size: 8 X $9 \mathrm{~mm}$

Manufacturer: Krautkramer

Straight-Beam

Type: MSEB 5B

Frequency: $5 \mathrm{MHz}$

Size: Dual - 9 X 2 mm

Manufacturer: Krautkramer

\section{Transducer Specifications:}

Angle-Beam

Type: MWB-45 04E

Frequency: $4 \mathrm{MHz}$

Size: 8 X $9 \mathrm{~mm}$

Manufacturer: Krautkramer

Figure 3.2. Transducer Configurations for Examination of Weld Zone in the Primary Tank Wall 
In the HAZ, the requirement for characterizing cracks that lie perpendicular or parallel to welds in the primary tank wall is described in Figure 3.3. The HAZs are located on either side of the weld and defined as being within 1-in. of the toe of the weld and on the inner three-quarters of the thickness (3/4T) of the plate. These zones are considered most likely to experience stress-corrosion cracking.
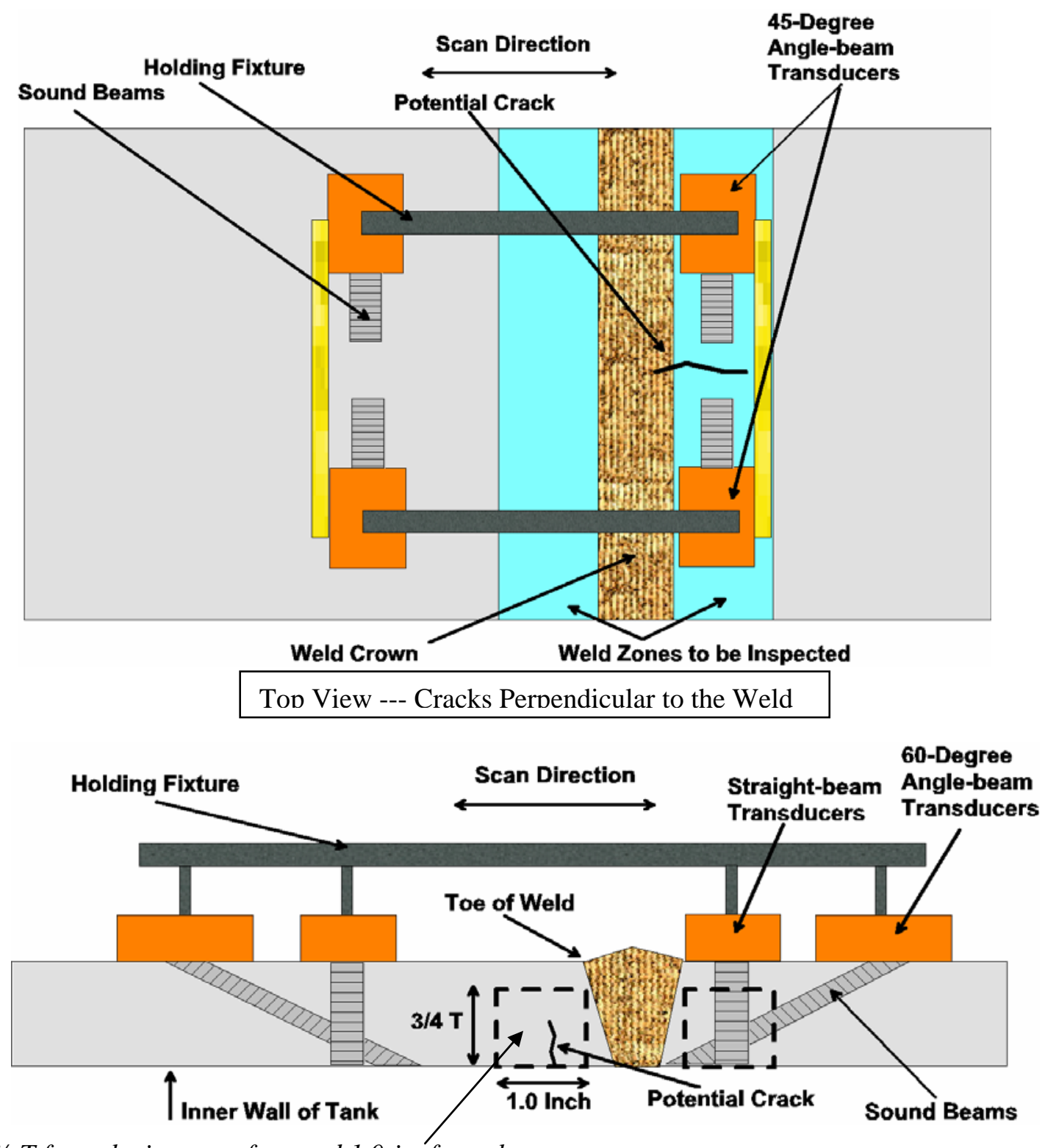

A zone $3 / 4 \mathrm{~T}$ from the inner surface and 1.0-in. from the toe of the weld is to be ultrasonically examined for cracking, corrosion or pitting. Examinations are to be made on both sides of the weld.

$$
\text { End View --- Cracks Parallel to the Weld }
$$

Figure 3.3. Views of the Weld Zone to be Ultrasonically Examined in the Primary Tank Wall 


\subsection{Ultrasonic Examination Location}

Tank 241-AW-103 is located in the Hanford 200 East area in AW Tank Farm. The crawler and associated scanner that hold the transducers were lowered into the 24-in. risers located on the east side (Riser 28) and on the west side (Riser 29) of 241-AW-103. Figure 4.1 provides a graphic of the location of the risers.
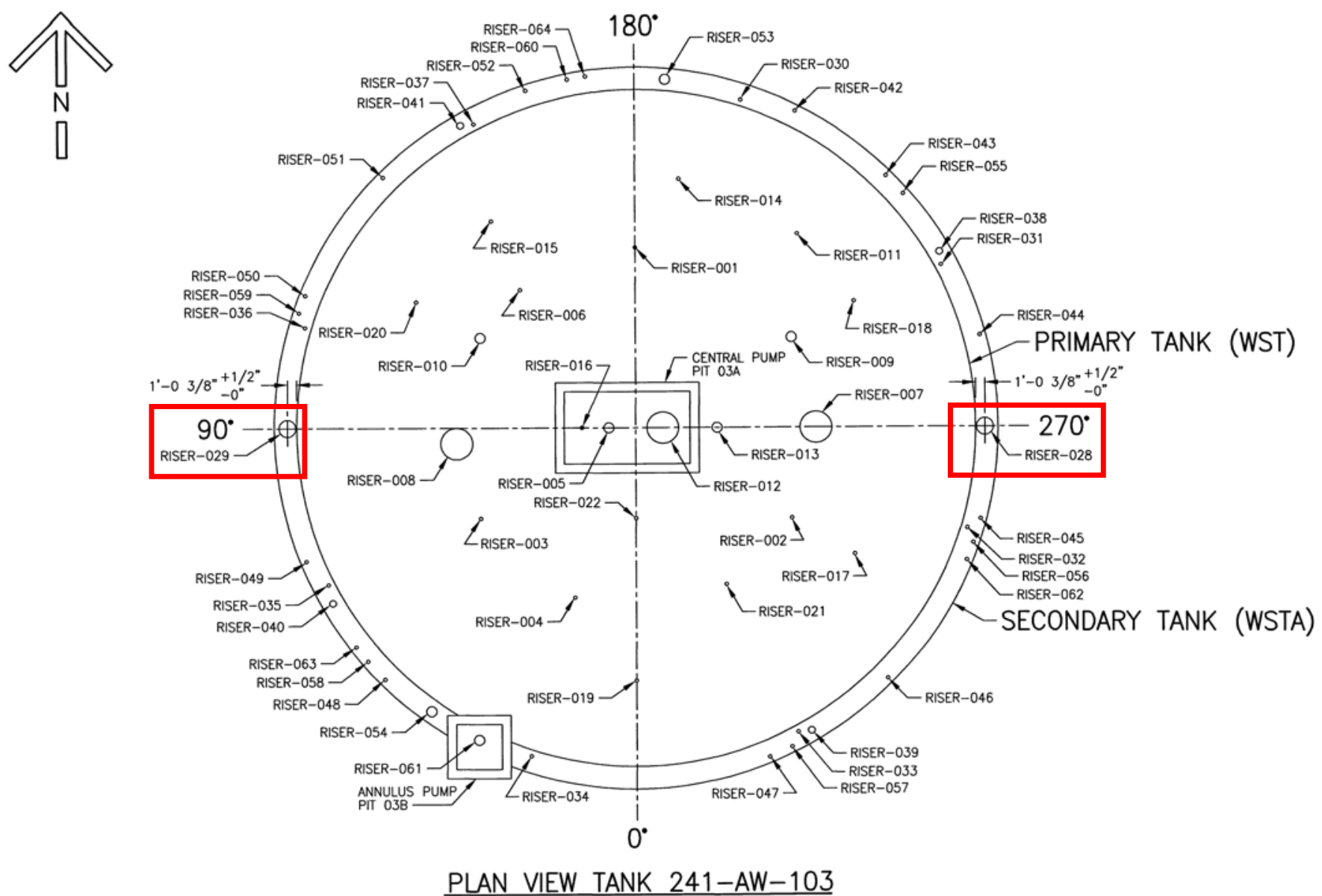

Figure 4.1. UT of Tank 241-AW-103 Riser 28 and Riser 29 
Figure 4.2 describes the areas on the primary wall of Tank 241-AW-103 that were ultrasonically examined from Riser 28 located on the east side of the tank. Two 15-in.-wide vertical scan paths were performed on Plates \#1, \#2, \#3, \#4, and \#5 below the entrance to Riser 28.

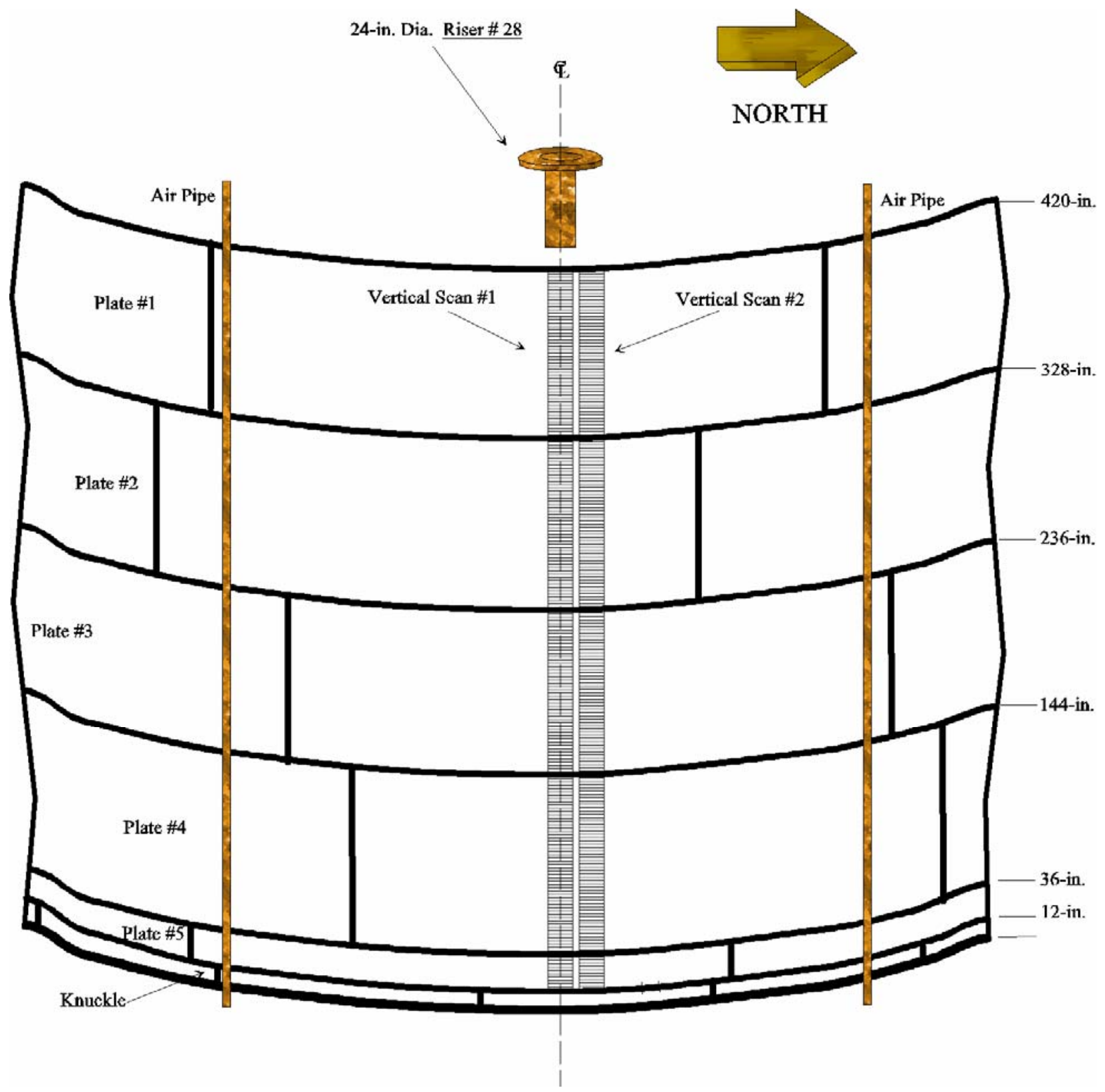

Figure 4.2. Sketch of Scan Paths on 241-AW-103 Primary Tank from Riser 28 
Figure 4.3 describes the areas on the primary wall of Tank 241-AW-103 that were ultrasonically examined from Riser 29 located on the west side of the tank. Two 15-in.-wide vertical scan paths were performed on Plates \#1, \#2, \#3, \#4, and \#5 below the entrance to Riser 29. Vertical weld HAZ examinations were done on Plates \#2, \#3, \#4, and \#5, and the horizontal weld HAZ examination was done on the transition Plate \#5 to knuckle weld.

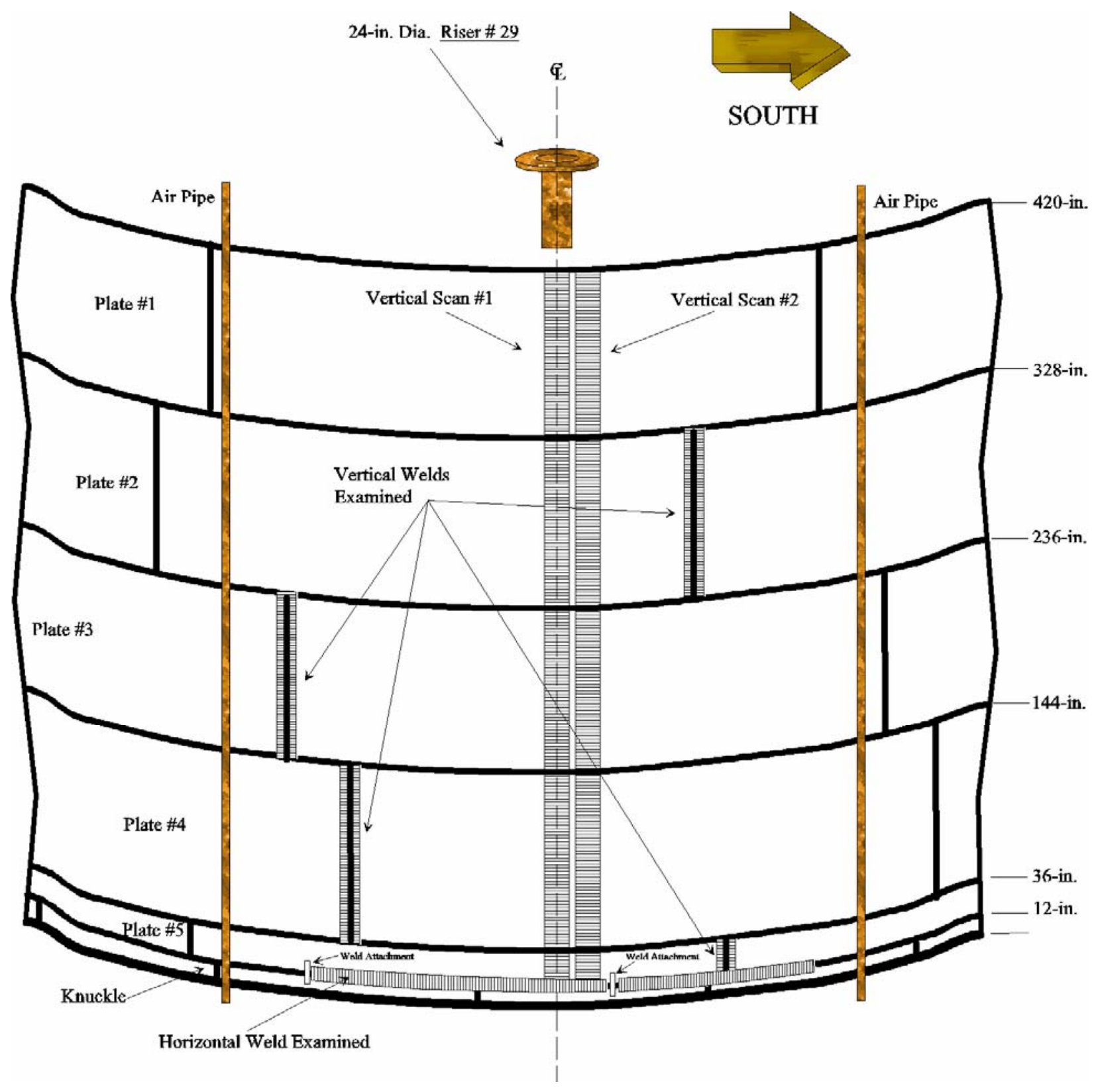

Figure 4.3. Sketch of Scan Paths on Tank 241-AW-103 Primary Tank from Riser 29 
Figure 4.4 describes the areas on the secondary wall of Tank 241-AW-103 that were ultrasonically examined from Riser 28 located on the east side of the tank. Two 15-in.-wide vertical scan paths were performed on Plates \#1, \#2, \#3, \#4, and \#5 below the entrance to Riser 28.

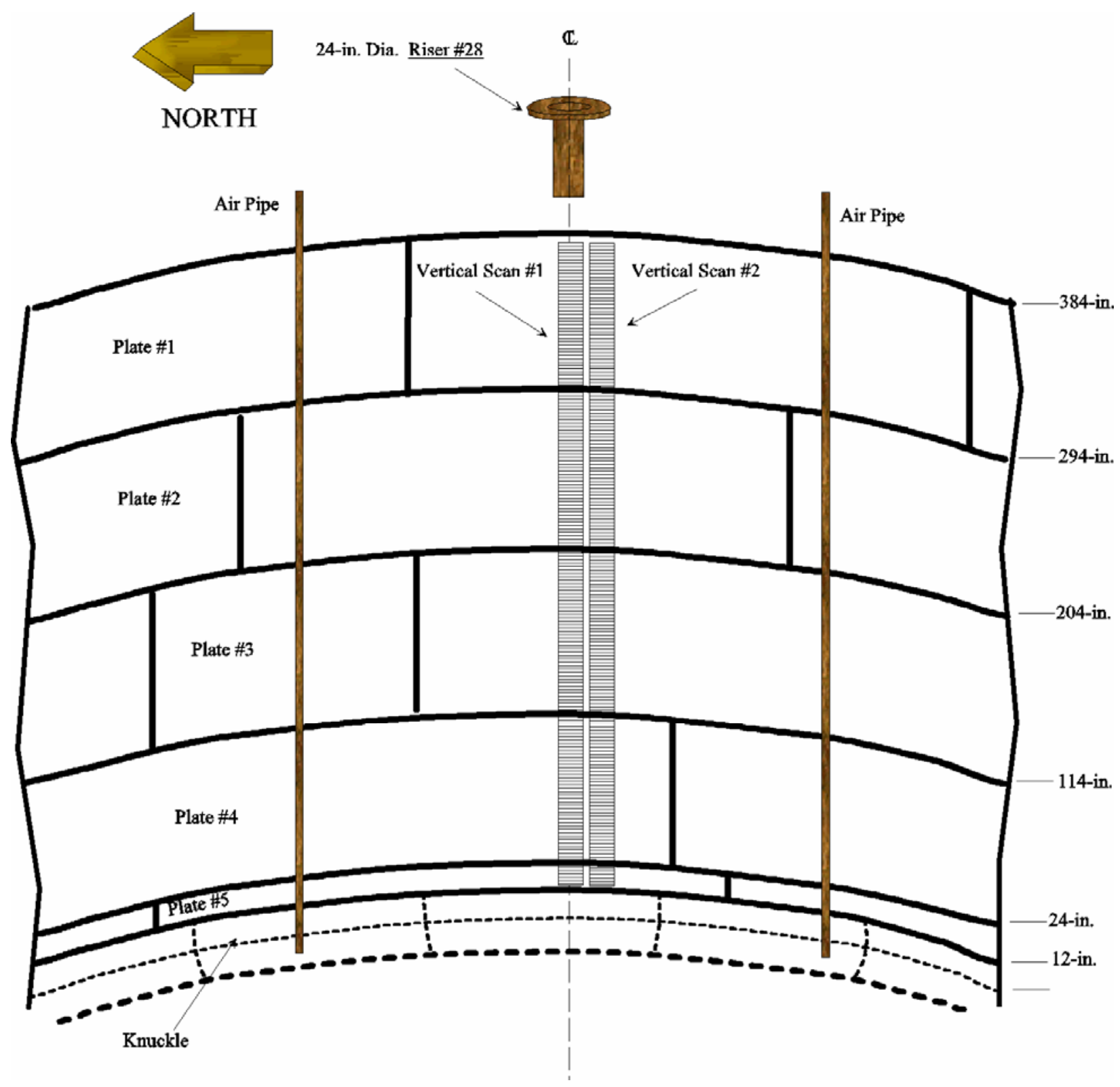

Figure 4.4. Sketch of Scan Paths on Tank 241-AW-103 Secondary Tank from Riser 28 


\subsection{Ultrasonic Examination Results}

AREVA has provided detailed reports including T-Scan and P-Scan hard copies of all areas that were ultrasonically examined to PNNL for third-party review. The data was analyzed by AREVA Level III Mr. Wes Nelson, and peer reviewed by JBNDT Level III Mr. Jim Elder. The results of the examination of Tank 241-AW-103 are presented in Figures 5.1 through 5.6.

Figures 5.1 and 5.2 show the wall thickness examination results for the primary tank wall from Riser 28. The examination consisted of two vertical paths beneath the 24-in. diameter riser. Vertical scan \#1 was 15-in.-wide on Plates \#1, \#2, \#3, \#4, and \#5 near the centerline of the 24-in. riser. Vertical scan \#2 was adjacent to vertical scan \#1 and was also 15-in.-wide on Plates \#1, \#2, \#3, \#4, and \#5. Vertical scans were conducted in the downward direction. Figures 5.1 and 5.2 display the minimum readings taken in each 15-in.-wide by 12-in.-long area of the scan.

Figures 5.3 and 5.4 show the wall thickness examination results for the primary tank wall and the HAZs of both vertical and horizontal welds from Riser 29. The examination consisted of two vertical paths beneath the 24 -in. diameter riser. Vertical scan \#1 was 15-in.-wide on Plate \#1, \#2, \#3, \#4, and \#5 near the centerline of the 24-in. riser. Vertical scan \#2 was adjacent to vertical scan \#1 and was also 15in.-wide on Plates \#1, \#2, \#3, \#4, and \#5. Vertical scans were conducted in the downward direction. The HAZs of vertical welds in Plates \#2, \#3, \#4, and \#5 were examined and the HAZ in the horizontal weld between Plate \#5 and the knuckle section was also examined. Weld area exams include approximately 5 -in. on each side of the weld. Areas in the figures that show two measurements in the same box are the result of the vertical scan paths overlapping the horizontal scan paths. Figures 5.3 and 5.4 display the minimum readings taken in each 15 -in.-wide by 12-in.-long area of the scan. In the overlapping areas, both minimum readings from each vertical and horizontal scan paths are given.

Figures 5.5 and 5.6 show the wall thickness examination results for the secondary tank wall from Riser 28. The examination consisted of two vertical paths beneath the 24-in. diameter riser. Vertical scan $\# 1$ was 15-in.-wide on Plates \#1, \#2, \#3, \#4, and \#5 near the centerline of the 24-in. riser. Vertical scan \#2 was adjacent to vertical scan \#1 and was also 15-in.-wide on Plates \#1, \#2, \#3, \#4, and \#5. Vertical scans were conducted in the downward direction. Figures 5.1 and 5.2 display the minimum readings taken in each 15-in.-wide by 12-in.-long area of the scan. 


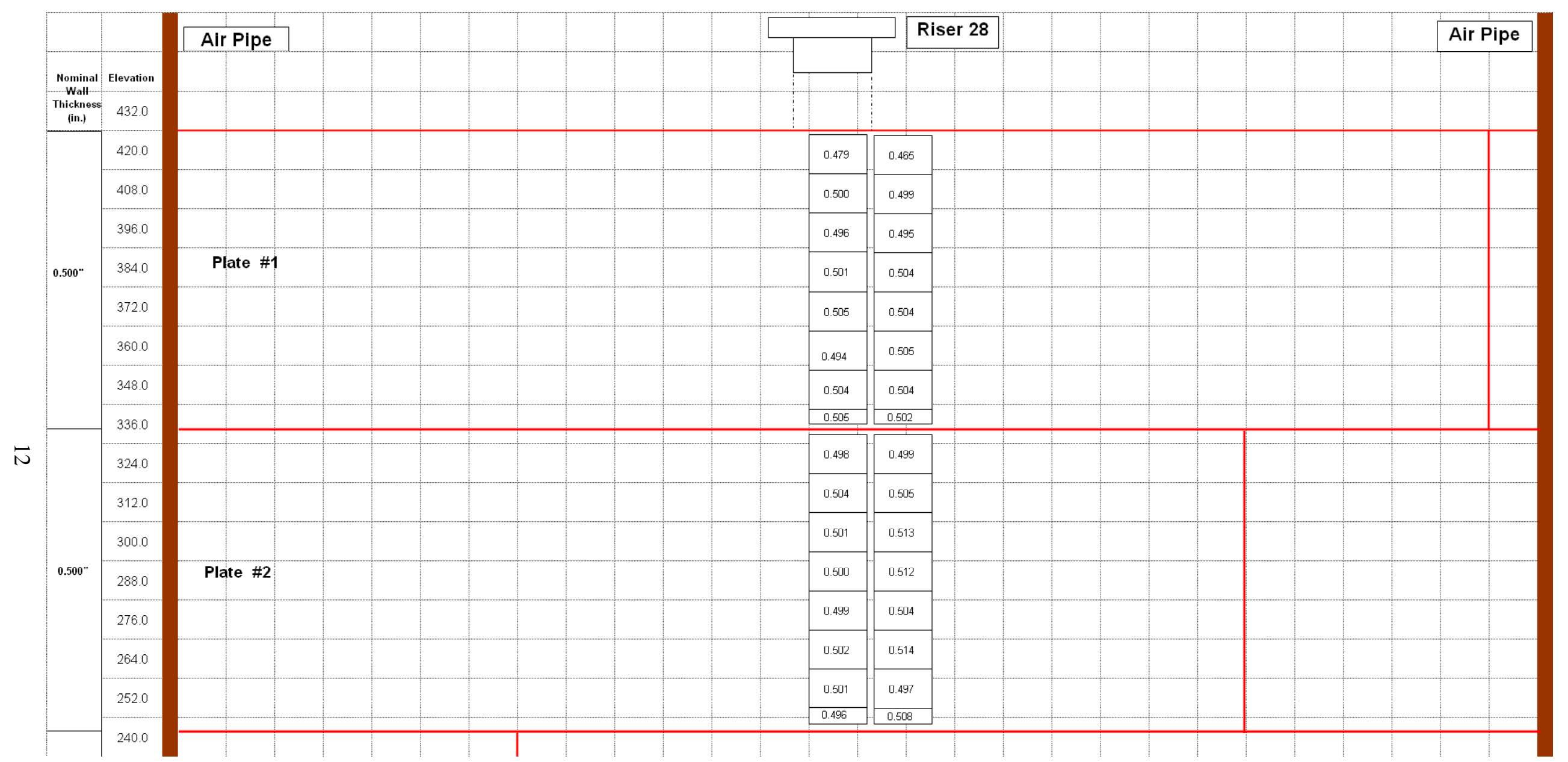

Figure 5.1. UT Data from Tank 241-AW-103 Primary Tank Riser 28 


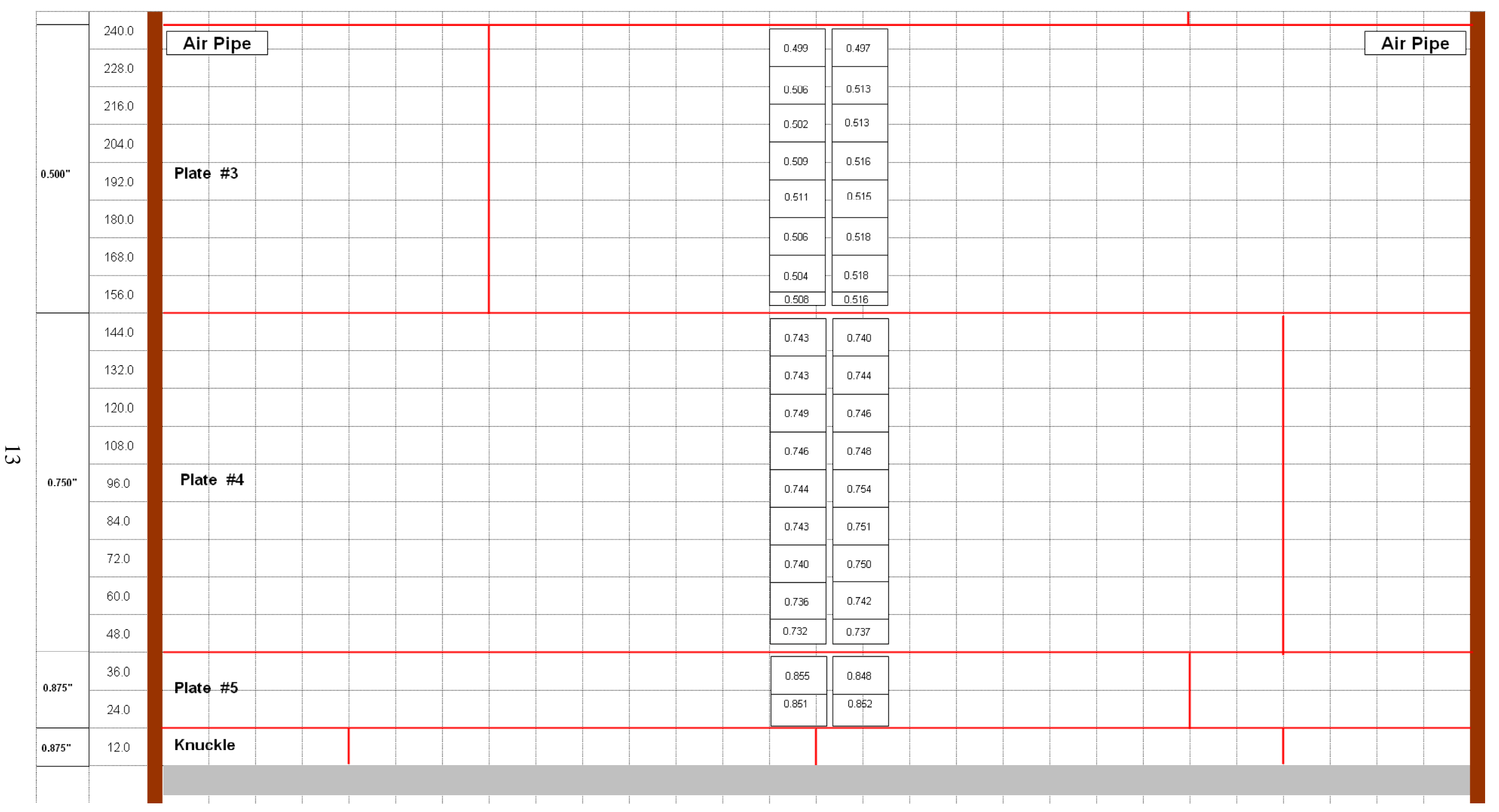

Figure 5.2. UT Data from Tank 241-AW-103 Primary Tank Riser 28 cont. 


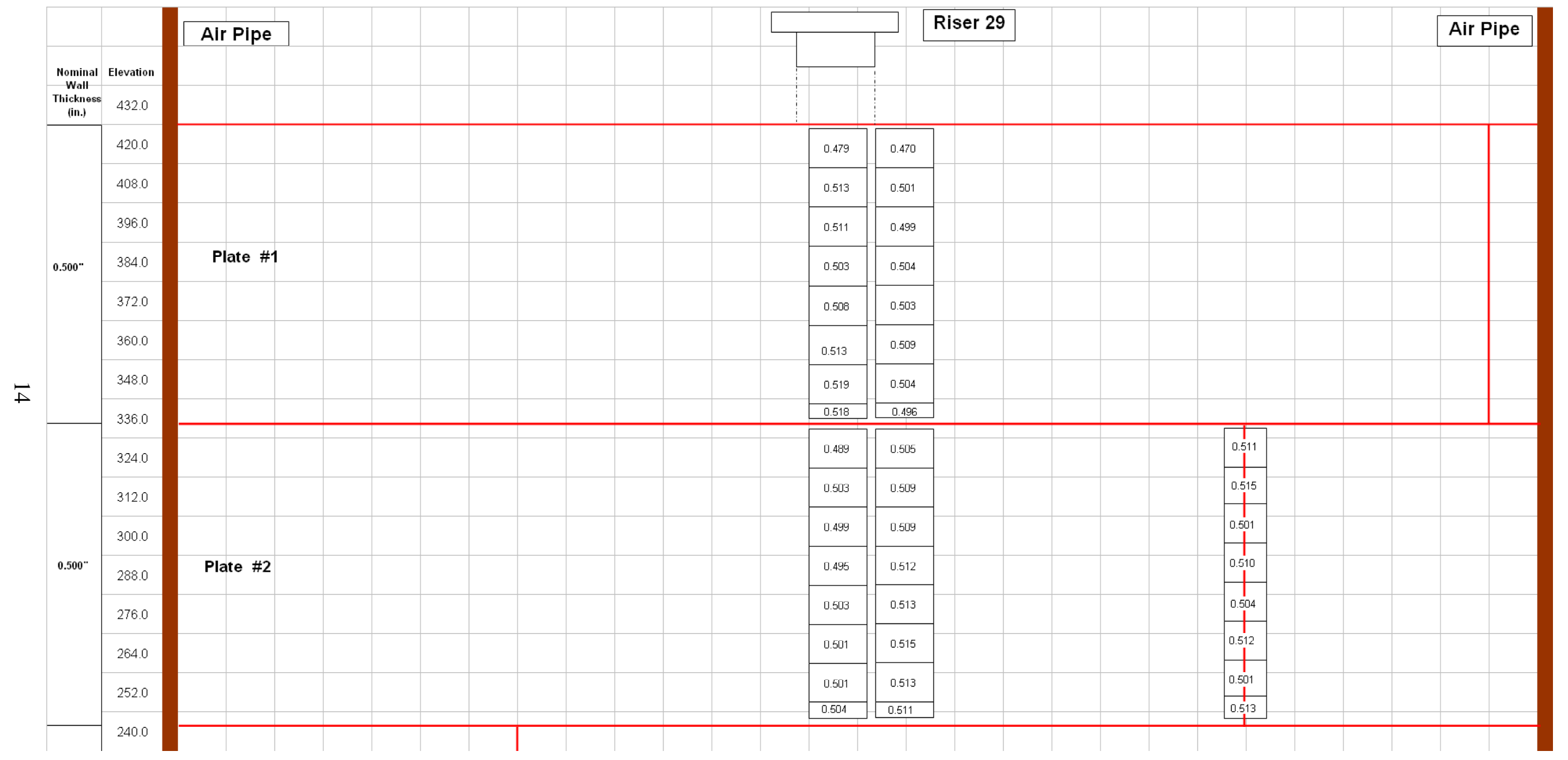

Figure 5.3. UT Data from Tank 241-AW-103 Primary Tank Riser 29 


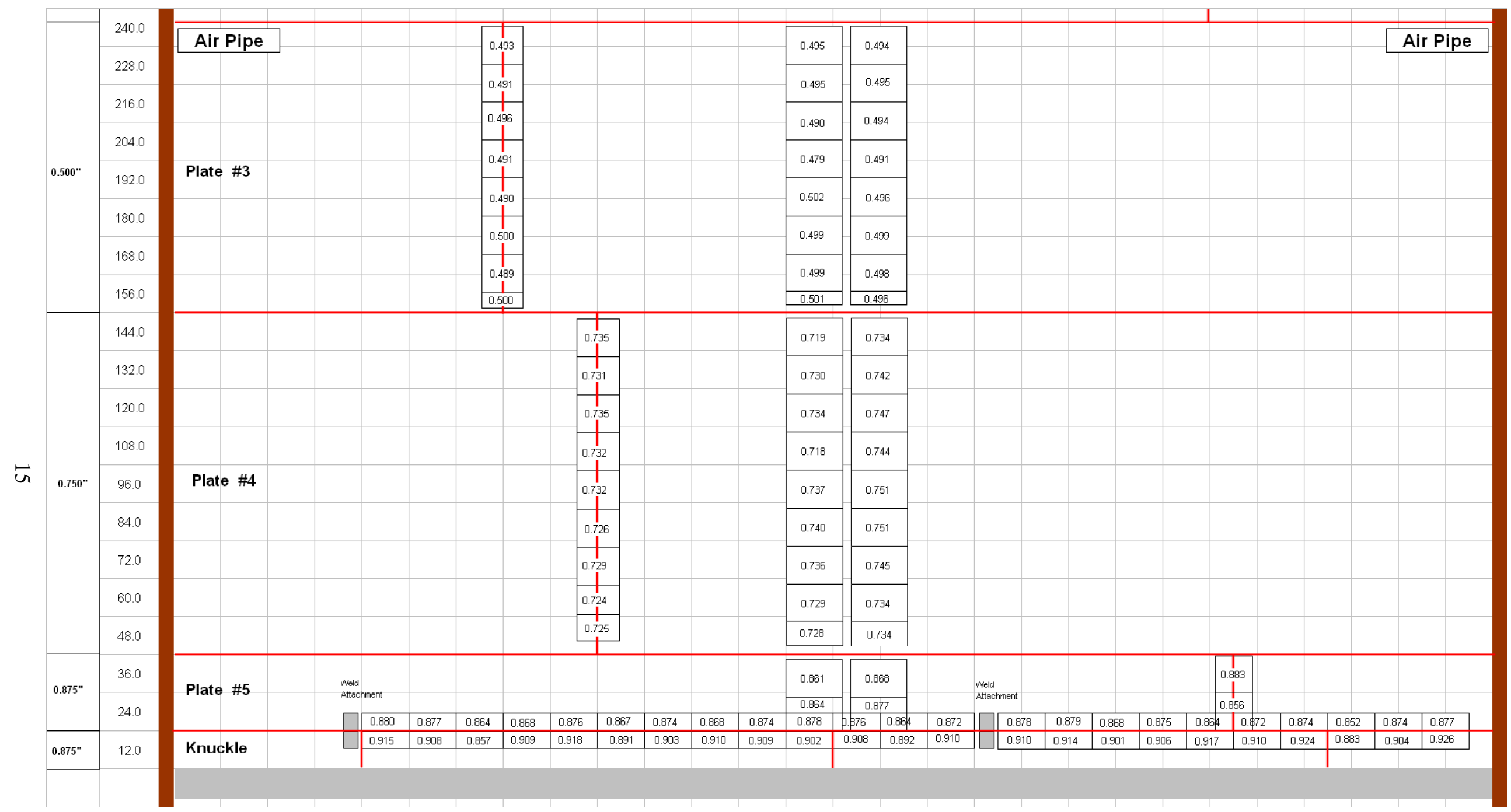

Figure 5.4. UT Data from Tank 241-AW-103 Primary Tank Riser 29 cont. 


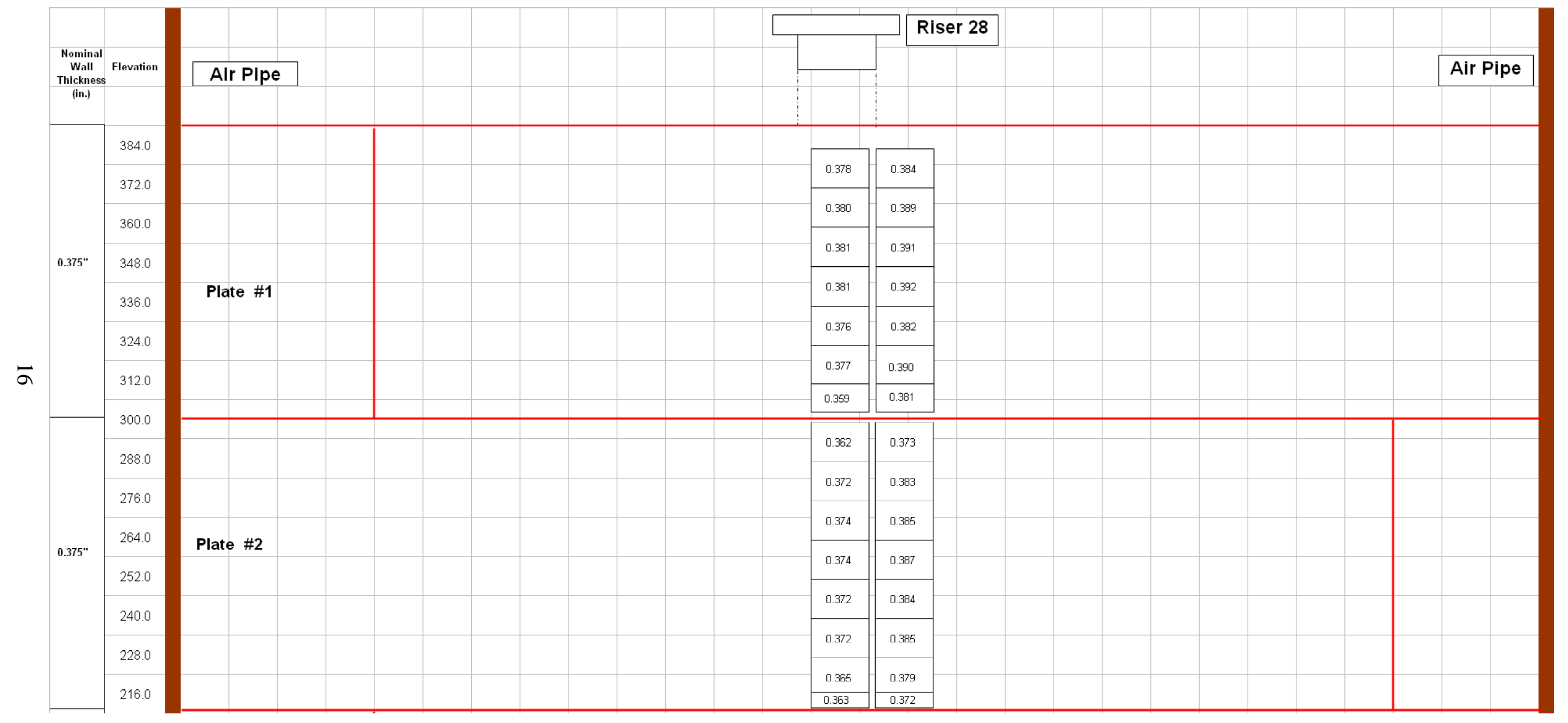

Figure 5.5. UT Data from Tank 241-AW-103 Secondary Tank Riser 28 


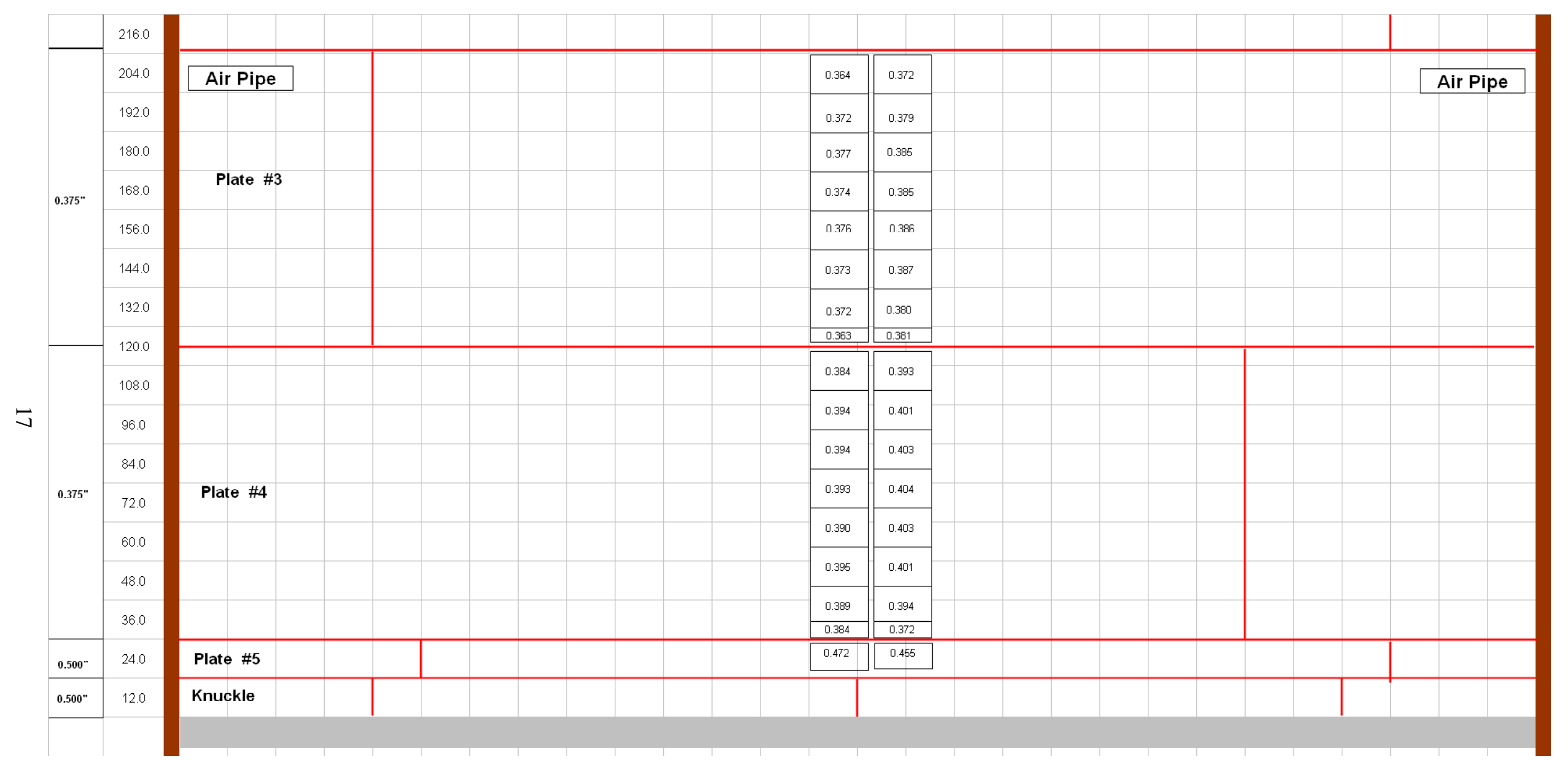

Figure 5.6. UT Data from Tank 241-AW-103 Secondary Tank Riser 28 cont. 


\subsection{Extreme Value Analysis}

The objective of this section is to estimate a worst case wall condition with respect to thinning (see Weier, Anderson, 2005, for a description of the methodology). If remaining wall thickness were used to estimate such a worst case condition, wall thickness measurements from plates with differing nominal thicknesses could not be combined to fit a common distribution. Extreme value distribution fitting will benefit from having more measurements to fit, so if results can be reasonably combined across plates, this approach is preferred. For this reason, extreme value plate loss is computed instead of using remaining wall thickness. However if the original nominal values for tank wall thicknesses of 0.500 -in., 0.750 -in., and 0.875-in. are used, negative losses are obtained since remaining wall thickness still exceeds drawing nominal. For this reason UT image maximum values were used to provide a better estimate of original wall thickness than the drawing nominal values. This assumes some areas of plates are in near pristine condition. But of course such maximum values would not be used if they were less than the original nominal thickness.

Note that measurement error and its variability has not been separated from the actual wall thickness variability here. Therefore when an extreme value is generated using the following methodologies, a worst case "measured wall thickness loss" is being estimated. That is, both the measurement variability and the actual wall thickness variability contribute to the uncertainty. When we obtain a worst case value, we are then deriving a worst case "measured result" that would be expected if the entire tank were inspected using UT methodology. This is a more extreme value than would be obtained by estimating only a worst case wall condition; to do that measurement error would have to be adequately characterized and removed from consideration. That has not yet been undertaken since appropriate data might not be available to do so, but it is a topic of ongoing analyses.

Two paths are available down each of two risers. For example, in a $~ 10$-ft. plate (vertical dimension) for one riser, this generates about 18 maximum measured wall thickness values (it actually varies from plate to plate depending on plate dimensions). These values were considered for each riser/plate combination. The alternative "nominal thickness" selected in this manner then depended somewhat on the pattern of these maximum values, but generally it could be described as approximately the $80^{\text {th }}$ percentile of such measurements. It was considered too extreme to use the largest of the 18 or so maximum values due to potential measurement error then grossly over-estimating the true nominal thickness. In this manner the Figure 6.1 maximum remaining thicknesses were obtained for Tank 241AW-103.

\begin{tabular}{|c|c|c|c|c|c|}
\hline \multirow{2}{*}{ AW-103 } & \multicolumn{5}{|c|}{ Plate Estimated Nominal } \\
\cline { 2 - 6 } & $\mathbf{1}$ & $\mathbf{2}$ & $\mathbf{3}$ & $\mathbf{4}$ & $\mathbf{5}$ \\
\hline \hline Riser 28 & 0.5375 & 0.5425 & 0.5475 & 0.7730 & 0.9000 \\
\hline Riser 29 & 0.5525 & 0.5475 & 0.5390 & 0.7775 & 0.9050 \\
\hline
\end{tabular}

Figure 6.1. Table of Estimated Nominal Thickness from UT Maxima

Then the 18 individual UT image minimum values for a plate/riser combination were subtracted from 
the estimated maximum value for that plate/riser from Figure 6.1. In this manner 18 estimated maximum wall thickness losses could be obtained for such a plate/riser combination, and then these were combined across the two risers, so about 36 such losses were available for the entire plate course. Note that since two risers are used, the riser variability within the tank does contribute to the overall variability in the results. For this reason an added one-sigma uncertainty, to accommodate riser variability if only a single riser were used, is not added here (see Weier, Anderson, Berman 2005).

The histograms in Figure 6.2 show such wall thickness loss data grouped by plate course. That is, the UT image maximum losses from the four paths, two per riser, within each plate course are combined. Three parameter Weibull distributions are fit to these histograms and are shown as the smooth curves. The total surface area of a plate course, and thus the number of 15-in. by 12-in. UT images needed to $100 \%$ inspect the plate course, is computed. The percentile of the distribution that then corresponds to the greatest expected loss among this many UT images, based on the distribution fit to the histogram, is

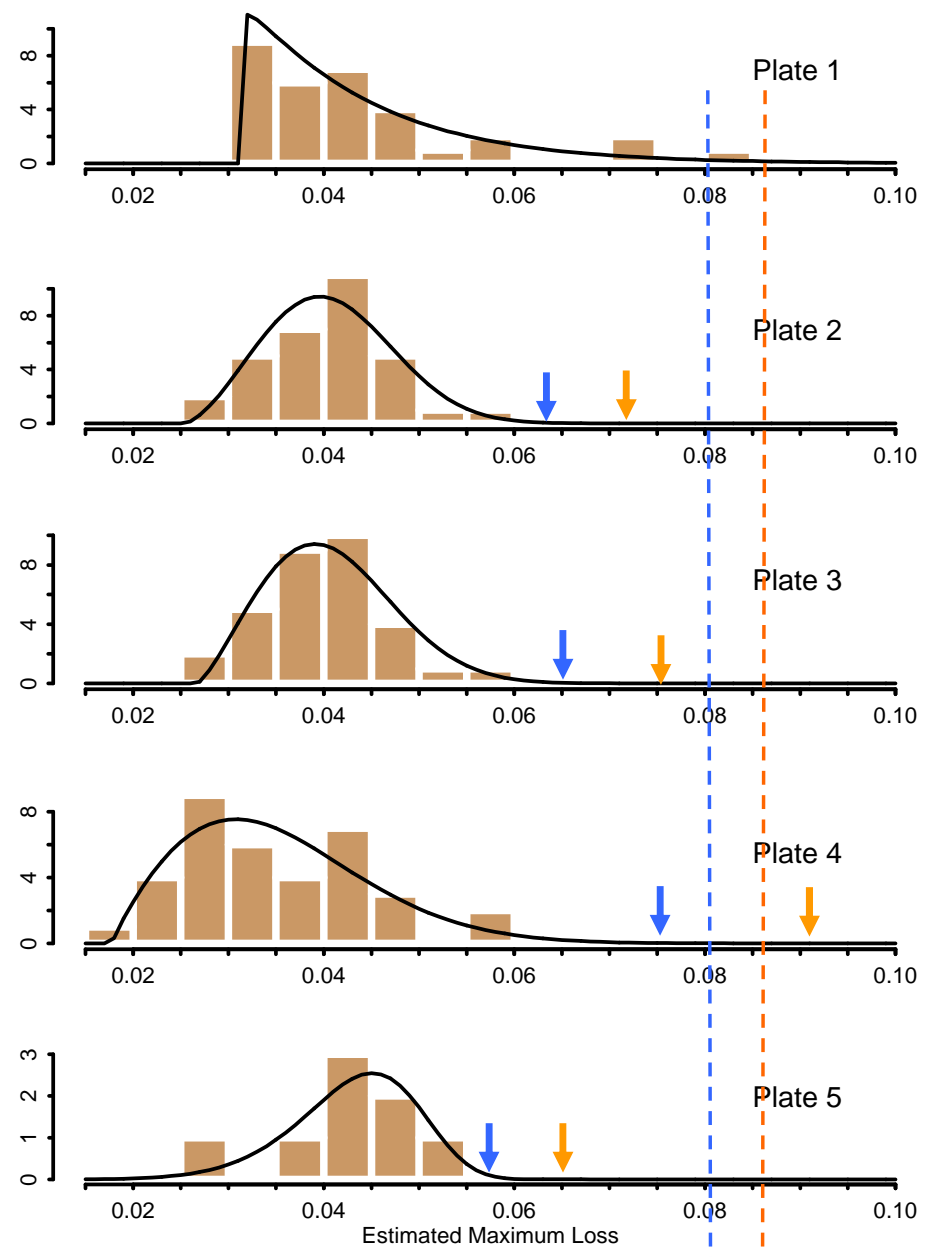

Figure 6.2. Weibull Distribution Fits to UT Maximum Wall Thickness Loss by Plate Course 
considered as the estimated worst case loss. But the number of measurements available and the quality of the fit of the Weibull distribution affect the uncertainty in the estimated Weibull parameters, and in turn, the uncertainty in the estimated worst case loss. Therefore $95 \%$ confidence bounds on the worst case values are also computed using these uncertainties.

The values indicated by the arrows on the histograms are the estimated worst case losses per plate course (blue) and their associated 95\% confidence bounds (orange). The corresponding values are given in the table shown in Figure 6.3. Included in the table are: 1) the number of measurements, 2) the estimated extreme value loss expected for the plate course around the entire circumference of the tank, and 3 ) the $95 \%$ confidence bound for the extreme loss for each plate and for a combination of the plate data. This combination is represented in Figure 6.2 by the blue and gold vertical dotted lines.

\begin{tabular}{|c|c|c|c|c|c|c|}
\hline AW-103 Extreme & \multicolumn{7}{|c|}{ Plates } \\
\hline Values & \multicolumn{7}{|c|}{} \\
\hline & Combined & $\mathbf{1}$ & $\mathbf{2}$ & $\mathbf{3}$ & $\mathbf{4}$ & $\mathbf{5}$ \\
\hline Estimate & 0.080 & 0.120 & 0.063 & 0.065 & 0.075 & 0.057 \\
\hline Bound & 0.086 & 0.160 & 0.072 & 0.075 & 0.091 & 0.065 \\
\hline Measurements & 140 & 32 & 32 & 32 & 36 & 8 \\
\hline
\end{tabular}

Figure 6.3. Table of Tank 241-AW-103 Wall Thickness Extreme Value Loss Estimates and Bounds

The Plate \#5 estimate and bound are rather small relative to the largest measured values, since the distribution that was fit actually tails more to small values than to large values. This is likely due more to the modest number of measurements for this plate and not to differences in the actual wall thickness loss mechanism for this plate.

Note that the Plate \#1 distribution fit is considerably influenced by the "pile-up" of measurements at the low end of the histogram and then the set of rather large outlying loss values larger than 0.070-in. In fact the usual convergence criteria for fitting the three-parameter Weibull could not be met in this case, and a "shift" parameter had to be specified rather than estimated. The magnitude of this shift parameter value, which actually addresses the left end of the distribution, has considerable impact on the length of the right-hand tail. This is unfortunate since the left-tail values then dramatically affect the extreme value estimates. In other words, the Plate \#1 results are not well-modeled using the three-parameter Weibull, and the resulting quite large estimates are somewhat suspect.

Those characteristics that give the quite large maximum loss estimate and bound for Plate \#1 can easily result from the relatively minimal amounts of data available for distribution fitting; therefore we are motivated to group the wall thickness losses across plate courses as much as possible. Such grouping would also be based on the assumption that the corrosion mechanism for the tank wall interior is reasonably consistent throughout the tank. However, this assumption might be more reasonable in some tanks than others. Certainly the measurements should be also analyzed by plate course as above as part of the determination of the appropriateness of subsequent grouping. 
If the three outlying values had not been obtained for Plate \#1, there would be little reason to think the wall thickness losses are different from plate to plate, especially in the upper tail of the distributions which is the area of most interest in this extreme value estimation. Under the assumptions that the large outlying values are legitimate values, and not due to some special measurement problem, and that the large values could have just as well been obtained from the other plates, the wall thickness losses are combined across all five plate courses for Tank 241-AW-103 and shown both in the table in Figure 6.3 above and in the histogram in Figure 6.4.

The extrapolation out to a tail percentile for the combined data has to accommodate the entire surface area of the tank across all five courses and therefore goes out to a higher percentile of the distribution. The estimate and bound in this combined case are shown by the arrows in Figure 6.4 and by the vertical dotted lines in Figure 6.2. These values are proposed as the most reasonable extreme value wall thickness loss estimates for Tank 241-AW-103.

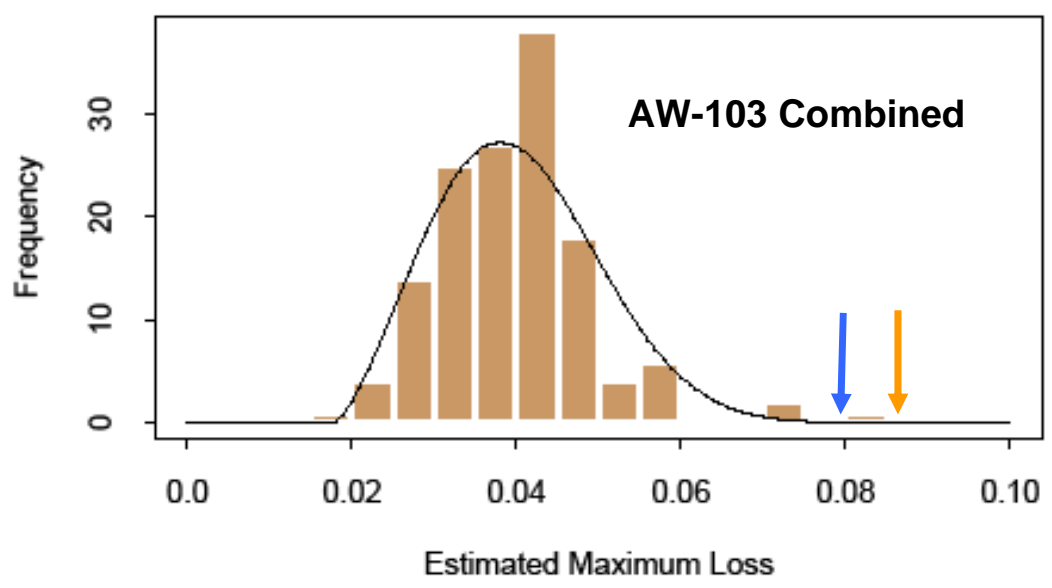

Figure 6.4. Weibull Distribution Fit to Maximum Wall Thickness Loss Combined over Plate Courses

In this manner 0.080 -in. is proposed as a worse case measured wall thickness loss if the entire surface of the tank walls were UT measured. But the uncertainty on this estimate results in a 95\% confidence bound on the true worse case measured loss as 0.086-in. It is important to note that if these loss values were applied to determine a worse case remaining thickness, drawing nominal thicknesses would not be used as the original tank wall thickness, but rather the estimated wall thicknesses given in the table in Figure 6.1. And recall that for Tank 241-AW-103 these estimated nominal thicknesses from the UT maxima were about 0.030-in. to 0.040-in. greater than drawing nominal.

The Plate \#1 results are somewhat disconcerting since the largest loss observed in these data does exceed the estimated extreme value, but at least it does not exceed the $95 \%$ confidence bound. If it is truly believed that a different corrosion mechanism could be affecting Plate \#1 than affects the other plates, then the suitability of grouping the results across all five plates could be questionable. Insufficient data are available to defend a determination either way. As has been shown, if Plate \#1 were treated separately, the poor Weibull fit results in much larger extreme value estimates. 


\subsection{Conclusions}

The results of the examination of Tank 241-AW-103 have been evaluated by PNNL personnel. The primary tank ultrasonic examination consisted of two vertical 15-in.-wide scan paths over the entire height of the tank, the heat-affected zone (HAZ) of four vertical welds and one horizontal weld from Riser 29 and two vertical 15-in.-wide scan paths over the entire height of the tank from Riser 28. Additionally, two vertical 15-in.-wide scan paths over the entire height of the secondary tank from Riser 28 were performed. The examinations were performed to detect any wall thinning, pitting, or cracking in the primary tank wall.

\subsection{Primary Tank Wall Vertical Scan Paths}

Two 15-in.-wide vertical scan paths were performed on Plates \#1, \#2, \#3, \#4, and \#5 from Riser 28. The plates were examined for wall thinning, pitting, and cracks oriented vertically on the primary tank wall. The results indicated that the minimum thicknesses in the areas that were scanned with nominal thickness of 0.500 -in. are as follows; Plate \#1 was 0.465 -in., Plate \#2 was 0.496 -in., and Plate \#3 was 0.497-in. The nominal thickness in Plate \#4 is 0.750-in. and the minimum thickness in this area was 0.732-in. The nominal thickness in Plate \#5 is 0.875 -in. and the minimum thickness in this area was 0.848 -in. There were no areas of wall thinning that exceeded the reportable level of $10 \%$ of the nominal thickness. No pitting or vertical crack-like indications were detected in Plates \#1, \#2, \#3, \#4, or \#5.

Two 15-in.-wide vertical scan paths were performed on Plates \#1, \#2, \#3, \#4, and \#5 from Riser 29. The plates were examined for wall thinning, pitting, and cracks oriented vertically on the primary tank wall. The results indicated that the minimum thicknesses in the areas that were scanned with nominal thickness of 0.500 -in. are as follows; Plate \#1 was 0.470 -in., Plate \#2 was 0.489 -in., and Plate \#3 was 0.479-in. The nominal thickness in Plate \#4 is 0.750-in. and the minimum thickness in this area was 0.718-in. The nominal thickness in Plate \#5 is 0.875-in. and the minimum thickness in this area was 0.861-in. There were no areas of wall thinning that exceeded the reportable level of $10 \%$ of the nominal thickness. No pitting or vertical crack-like indications were detected in Plates \#1, \#2, \#3, \#4, or \#5.

\subsection{Primary Tank Wall Weld Scan Paths}

The HAZ of vertical welds in Plates \#2, \#3, \#4, and \#5 from Riser 29 were examined for wall thinning, pitting and cracks oriented either perpendicular or parallel to the weld. The results indicated that the minimum thicknesses in the weld areas that were scanned are as follows: The nominal thickness of Plate \#2 is 0.500-in. and the minimum thickness in this weld area was 0.501-in. The nominal thickness in Plate \#3 is 0.500-in. and the minimum thickness in this weld area was 0.491-in. The nominal thickness in Plate \#4 is 0.750-in. and the minimum thickness in this weld area was 0.724-in. The nominal thickness in Plate \#5 is 0.875 -in. and the minimum thickness in this weld area was 0.856 -in. There were no areas of wall thinning that exceeded the reportable level of $10 \%$ of the nominal thickness. No pitting or crack-like indications were detected in the weld areas in Plates \#2, \#3, \#4, and \#5. 
The HAZ of the horizontal weld between Plate \#5 and the tank knuckle from Riser 29 was examined for wall thinning, pitting and cracks oriented either perpendicular or parallel to the weld. The results indicated that the minimum thickness in the weld area with nominal thickness of 0.875 -in. on Plate \#5 was 0.852 -in. The minimum thickness in the weld area with nominal thickness of 0.875 -in. on the knuckle was 0.857 -in. There were no areas of wall thinning that exceeded the reportable level of $10 \%$ of the nominal thickness. No pitting or crack-like indications were detected in the weld areas on Plate \#5 side or on the knuckle side of the horizontal weld.

\subsection{Secondary Tank Wall Vertical Scan Paths}

Two 15-in.-wide vertical scan paths were performed on the secondary tank wall on Plates \#1, \#2, \#3, \#4, and \#5 from Riser 28. The plates were examined for wall thinning, pitting, and cracks oriented vertically on the secondary tank wall. The results indicated that the minimum thicknesses in the areas that were scanned with nominal thickness of 0.375 -in. are as follows; Plate \#1 was 0.359 -in., Plate \#2 was 0.362-in., Plate \#3 was 0.363-in., and Plate \#4 was 0.372-in. The nominal thickness in Plate \#5 is 0.500in. and the minimum thickness in this area was 0.455 -in. There were no areas of wall thinning that exceeded the reportable level of $10 \%$ of the nominal thickness. No pitting or vertical crack-like indications were detected in Plates \#1, \#2, \#3, \#4, or \#5.

\subsection{Extreme Value Analysis}

Since current remaining wall thickness typically still exceeds drawing nominal, thereby generating negative losses, UT image maximum values were instead used to determine estimated nominal wall thickness per plate/riser combination. These thicknesses tended to run 0.030 to 0.040 -in. greater than drawing nominal. They in turn were used with each UT image minimum value to determine estimated wall thickness losses which were then combined for a plate course over the two risers, two UT measurement paths per riser.

Three parameter Weibull distributions were fit to the plate course measurements as well as to the measurements combined over all plates. The latter case leads to a proposed worst case measured wall thickness loss of 0.080-in. that might be expected if the entire surface area of the tank wall were UT inspected. A 95\% confidence bound is computed based on the uncertainty in the Weibull parameters caused by the relatively minimal amounts of data for distribution fitting and the quality of the Weibull fit; this $95 \%$ bound on measured wall thickness loss is 0.086 -in. Note that such losses should be considered relative to the larger "estimated" nominal wall thicknesses and not the drawing nominal.

Three rather large outlying losses for Plate \#1 bring into some question the suitability of combining this plate with the others to obtain these combined extreme value estimates. However, when Plate \#1 is treated alone, a large number of quite small losses, combined with three large outlying values, results in a poor distributional fit and quite large extreme values for the plate by itself. Insufficient data are available to identify the preferred approach between combining plate measurements or isolating those from Plate $\# 1$. 


\subsection{References}

Posakony GJ and AF Pardini. 1998. Final Report - Ultrasonic Examination of Double-Shell Tank 241AW-103, PNNL-11971, Pacific Northwest National Laboratory, Richland, Washington.

A. F. Pardini to C.E. Jensen dated August 22, 2000, Letter Report on Performance Demonstration Test PDT, May 2000. Copy on file in the PNNL DST Project Records.

G. J. Posakony to C.E. Jensen dated October 5, 2001, Letter Purdy Performance Demonstration Test (PDT) Report. Copy on file in the PNNL DST Project Records.

Jensen, C. E., 2005, Engineering Task Plan for the Ultrasonic Inspection of Hanford Double-Shell Tanks FY2006 and FY2007, RPP-PLAN-27202, Rev 0, October 2005, CH2M Hill Hanford Group, Inc., Richland, Washington.

Weier DR, and KK Andersen. 2005. Estimation of Maximum Wall Thickness Loss of Five DSTs (AW103, AP-102, AW-101, AZ-102, and SY-101), PNNL-15415, Pacific Northwest National Laboratory, Richland, Washington.

Weier DR, KK Andersen, and HS Berman. 2005. Riser Difference Uncertainty Methodology Based on Tank AY-101 Wall Thickness Measurements with Application to Tank AW-103, PNNL-15182, Pacific Northwest National Laboratory, Richland, Washington. 


\section{Distribution}

No. of

Copies

\section{Hanford Site}

J. L. Castleberry (1) R3-26

5 Pacific Northwest National Laboratory
S. L. Crawford (1)
K5-26
A. F. Pardini (1)
$\mathrm{K} 5-26$
G. J. Posakony (1)
K5-26
M. L. Watkins (1)
K5-26
D. R. Weier (1)
K6-08 